\title{
SOCIEDAD CIVIL SOBERANA Y ESTADO NEOCONSTITUCIONAL EN DERECHOS DE TERCERA GENERACIÓN
}

\author{
Sovereign civil society and neoconstitutional state in third generation rights
}

\begin{abstract}
Si la vida democrática no implica nada más que un voto periódico, el lugar para la actividad de las personas será el recinto (privado) de la sociedad civil [...] David Held
\end{abstract}

\author{
José Ángel MÉNDEZ RIVERA* \\ Enoc Francisco MORÁN TORRES H $^{* *}$
}

\begin{abstract}
Sumario
I. Introducción II. La crisis del Estado Soberano III. Derechos de Tercera Generación y Sociedad Civil Soberana IV. Estado Neoconstitucional y Democracia Participativa Soberana V. Conclusiones. VI. Fuentes de consulta
\end{abstract}

\begin{abstract}
Resumen: La aportación académica plantea la posibilidad de rediseñar constitucionalmente el concepto de soberanía, sustentado en una sociedad civil soberana para efectos de la democracia participativa en políticas públicas de derechos colectivos $y$, en el pueblo soberano para efecto de la democracia representativa. Ello, en aras de que en la praxis política real se logre un Estado Neoconstitucional en derechos de tercera generación.
\end{abstract}

Palabras clave: sociedad civil, soberanía, democracia participativa, democracia representativa, derechos colectivos, políticas públicas, estado neoconstitucional.

Abstract: The academic contribution, raises the possibility of redesigning, in a constitutionally way, the concept of sovereignty, sustained in a sovereign civil society for the purpose of Participatory Democracy in Public Policies of collective rights, and in the sovereign people for the representative democracy. This, in the interests of real political praxis, achieves a neoconstitutional state in thirdgeneration rights.

Key words: civil society, sovereignty, participatory democracy, representative democracy, collective rights, public policies, neoconstitutional state

* Profesor Investigador de Tiempo Completo de la Facultad de Derecho de la Universidad de Colima y Miembro del Sistema Nacional de Investigadores del CONACYT, México; Líder del Cuerpo Académico UCOL-CA-72 "Derecho Constitucional" de la Universidad de Colima.

**Profesor Investigador de Tiempo Completo de la Facultad de Derecho de la Universidad de Colima y Miembro del Sistema Nacional de Investigadores del CONACYT, México; Integrante del Cuerpo Académico UCOLCA-72 "Derecho Constitucional" de la Universidad de Colima 


\section{Introducción}

Si rediseñamos constitucionalmente el concepto de soberanía y lo sustentamos en una sociedad civil soberana, para efectos de la democracia participativa en políticas públicas de derechos colectivos o de tercera generación, y en el pueblo soberano para efecto de la Democracia Representativa; en la praxis política real, resultaría un Estado Neoconstitucional en derechos de tercera generación que sustentarán la política pública como obligación constitucional. Sirvan como primera aproximación al tema las siguientes preguntas.

¿Qué pasaría en la praxis política real si rediseñamos constitucionalmente el concepto de soberanía y lo sustentamos en una sociedad civil soberana para efectos de la Democracia Participativa y en el pueblo soberano para efecto de la Democracia Representativa?

¿Por ese principio de soberanía de la sociedad civil quedarían mejor protegidos los derechos colectivos, cuando el gobierno por exigencia constitucional tendría que evaluar periódicamente, mediante mecanismos de democracia participativa, las políticas públicas de tales derechos, lo que nos llevaría a un Estado verdaderamente neoconstitucional en derechos de tercera generación?

Para lo anterior, hay que retomar el concepto de soberanía popular, entendida como el principio legitimador que faculta a los órganos del Estado para representarnos, de manera que permita imponer obediencia y aceptación a las decisiones de dichos órganos, por el simple hecho de haber sido elegidos por una mayoría. Aun cuando la ciudadanía como pueblo, pueda o no enterarse de las decisiones de sus representantes.

Por otro lado, tomando la idea de soberanía nacional, como aquella ejercida por la sociedad civil, donde ésta es gobernante y demandante a la vez, pues postula que la organización del Estado y el modo en que se ejerce el poder, es mediante el consentimiento de la ciudadanía organizada y es ésta, la que determinará la acción del Estado a través de su opinión y decisión mediante la democracia participativa.

En esa línea argumentativa, introducir una sociedad civil soberana, en el marco de las interrogantes planteadas, implicaría que mientras el pueblo es representado a través del ejercicios de democracia representativa; la sociedad civil tendría la oportunidad de manifestar su conformidad o no con la toma de decisiones de los órganos del Estado a través de consultas, iniciativas y otros instrumentos de democracia participativa.

\section{La crisis del estado soberano}

Por lo menos desde fines de la década de los 8o's, se acrecentó una crítica a la eficiencia y extensión del Estado en América Latina, desde una perspectiva neoliberal, criticándose su baja eficiencia, alto costo, clientelismo político e irracionalidad administrativa. Como respuesta, la reforma del Estado en diversos países latinoamericanos, incluido México, estuvo sesgada por las perspectivas neoliberales en sentido estricto. Los énfasis se pusieron en el mercado y, el Estado sería un elemento para asegurar su funcionamiento, en especial los mercados transnacionales. La corriente generalizada fue la reducción del aparato estatal: se disminuyó el número de empresas públicas y las áreas en las cuáles intervenía o que regulaba el Estado.

Así, las reformas señaladas llevaron a lo que conocemos como el Estado neoliberal con prevalencia del mercado transnacional sobre los estados nacionales, surgiendo también un fenómeno paralelo: la exigencia de derechos colectivos como los derechos de tercera generación, bajo la 
presión particularmente de organismos de la sociedad civil. En estos casos, las organizaciones de sociedad civil por un lado piden una mayor presencia del Estado, que garanticen tales derechos. Pero por otro, actores políticos de corte conservador y fuerzas representantes del mercado, solicitan continuar el proceso de reducción del Estado. Incluso algunas organizaciones ciudadanas asumen posturas que apelan por un Estado mínimo, donde deberían darse ciertos tipos de autogestiones comunitarias.

En toda esta problemática no ha existido una discusión profunda sobre qué tipo de reforma del Estado es necesaria para construir un diseño constitucional que dé sustentabilidad a los derechos colectivos en función de la sociedad civil, ya que es ésta, a través de sus diversas organizaciones, la más legitimada para exigir derechos de tercera generación, por ejemplo desde el campo de las organizaciones no gubernamentales, pero no sólo para exigir estos derechos, sino también para participar en la formulación de las políticas públicas que atiendan la satisfacción de tales derechos, por lo que resulta fundamental preguntarse y plantearse:

¿Qué tipo de Estado sería necesario para los problemas de una democracia participativa en derechos de tercera generación, si en el diseño constitucional tradicional no tienen sustentabilidad tales derechos?, esto es, no están asegurados a largo plazo, porque en el diseño constitucional prevalece el concepto de soberanía sustentado en la democracia indirecta de carácter electoral en la que el gran actor es el pueblo como mero conjunto de votantes que elige representantes

\section{Derechos de tercera generación y sociedad civil soberana}

Los derechos de tercera generación ${ }^{1}$ son derechos colectivos también llamados derechos de los pueblos, que comenzaron a gestarse a partir de la Segunda Guerra Mundial, en la segunda mitad del siglo XX. El sujeto protegido ya no es el individuo en sí mismo, como en los de primera generación, o por su rol social, como en los de segunda generación, sino por integrar un pueblo, una nación, o ser parte de toda la humanidad. En este tenor se toma en cuenta a las personas, como integrantes de una comunidad con conciencia de identidad colectiva.

Con los procesos de descolonización e independencia de los llamados países periféricos africanos y asiáticos de Europa, estos nuevos estados reclamaron su autodeterminación política, social, económica y cultural, con lo que nació el derecho a la libre determinación de los pueblos y a su desarrollo económico y cultural. Para garantizar este derecho colectivo, el 16 de diciembre de 1966, la Asamblea General de las Naciones Unidas adoptó El Pacto Internacional de Derechos Civiles y Políticos ${ }^{2}$ y el Pacto Internacional de Derechos Económicos, Sociales y Culturales 3 instrumentos en los que consagra estos derechos como derechos de tercera generación.

Paralelamente, el desarrollo fabril y tecnológico sumado a la explotación desmedida e irracional de los recursos generó drásticas consecuencias ambientales, poniendo en riesgo a la humanidad presente y futura. El derecho a un ambiente sano surge como derecho de tercera generación en este contexto para defender el hábitat sin el cual ningún derecho podría ser ejercido,

\footnotetext{
1 Pérez Luño, Antonio (2006), La tercera Generación de los Derechos Humanos, Aranzadi, España, p. 25-3o.

2 Organización de las Naciones Unidas (1966), Pacto Internacional de Derechos Civiles y Políticos, 16 de diciembre, [en linea], disponible en: http://www.ohchr.org/SP/ProfessionalInterest/Pages/CCPR.aspx.

3 Organización de las Naciones Unidas (1966), Pacto Internacional de Derechos Económicos, Sociales y Culturales, 16 de diciembre, [en linea], disponible en: http://www.ohchr.org/SP/ProfessionalInterest/Pages/CCPR.aspx.
} 
ya que significaría al igual que lo expresado con el uso de armas químicas, la desaparición de nuestro planeta.

Otros derechos de tercera generación son: el respeto a las minorías étnicas, como los aborígenes que bregan por el reconocimiento de su cultura; el derecho a la identidad, perdido por muchos niños secuestrados por las dictaduras militares, entregados a familias en adopción, quienes los inscribieron como propios y; los derechos del consumidor (el grupo económico mayoritario en el mercado), desprotegido ante las grandes empresas, que los hacen suscribir contratos de adhesión con cláusula unilaterales que les ejercer derechos o, cuando se compran productos transgénicos no regulados y riesgosos para el medio ambiente.

La Segunda Guerra Mundial había dejado un sabor amargo de muerte y destrucción, el mundo se propuso no volver a sufrir calamidad semejante. Sin embargo, el riesgo subsistía con la conformación de dos bloques política y económicamente antagónicos: el capitalista, bajo el liderazgo de Estados Unidos, y el Socialista, bajo la influencia de la Unión Soviética. Estos bloques se estaban armando con armas nucleares, poniendo en peligro la existencia misma de toda la comunidad internacional. Por eso surgió la necesidad de postular otro derecho de tercera generación: el derecho a la paz como deber sagrado de los Estados ${ }^{4}$.

El 4 de julio de 1976 la Organización de las Naciones Unidas dictó la Declaración Universal de los Derechos de los Pueblos, donde consagró el derecho soberano de los pueblos a existir, a auto determinarse, a liberarse de toda dominación extranjera, a poseer un régimen democrático, una identidad nacional y cultural, a conservar la posesión de su territorio en paz, y gozar de sus recursos, de hablar su propia lengua y, los integrantes de un pueblo, a no ser expulsados, torturados, perseguidos o deportados, por su identidad nacional o cultural. Cada estado ha ido incorporando a sus constituciones, paulatinamente, durante los siglos XX y XXI, los llamados derechos de tercera generación, que es necesario analizar en el contexto de la soberanía y de la sociedad civil que demanda tales derechos.

En la teorización de la Soberanía ${ }^{5}$, se dice que es la suprema potestad que tiene un pueblo de actuar conforme sea su voluntad. Para Rousseau, el soberano es el pueblo. Sin embargo, cada ciudadano es soberano y súbdito al mismo tiempo, ya que contribuye a la creación de la autoridad (por lo tanto forma parte de ella) pero a su vez se encuentra sometido a esta misma autoridad y está obligado a obedecerla.

De esta forma, para Rousseau todos los ciudadanos son libres e iguales, ya que no son mandados por un individuo en específico, sino que reciben las órdenes de un sujeto indeterminado que representaría la voluntad general.

Si bien Rousseau fue el máximo responsable del concepto de soberanía popular, fue Sieyès quien se encargó de desarrollar la noción de soberanía nacional. Para Sieyès, la soberanía está radicada en la nación y no en el pueblo, ya que también se debe tener en cuenta el legado histórico y cultural y los valores bajo los cuales se ha fundado dicha nación. Sin embargo, en este texto, atenderemos al principio de que la soberanía reside en el pueblo para el ejercicio de la

\footnotetext{
4 En 1984, en el marco de la Declaración sobre el derecho de los pueblos a la paz, se determinó que para asegurar el ejercicio del derecho de los pueblos a la paz se requería que la política de los Estados esté orientada hacia la eliminación de la amenaza de la guerra, a la renuncia del uso de la fuerza en las relaciones internacionales y el arreglo de las controversias internacionales por medios pacíficos. Véase Organización de las Naciones Unidas (1984), Declaración sobre el derecho de los pueblos a la paz, 12 de noviembre [en línea], disponible en: http://www. ohchr.org/SP/Professionalinterest/Pages/RightOfPeoplesToPeace.aspx

5 Paoli Bolio, Francisco José (2009), Teoría del Estado, Trillas, México, p.194.
} 
democracia indirecta o representativa y, en la sociedad civil para el ejercicio de la democracia directa o participativa.

En las constituciones políticas generalmente está establecido que la soberanía reside en el pueblo, quien la transfiere a aquellas autoridades que elige para que la gobierne, es decir, cada ciudadano mediante su voto y como parte del pueblo transfiere autoridad a los gobernantes para que en nombre de ellos gobiernen. Así sucede en la constitución federal mexicana que en su artículo 39 establece que la soberanía nacional reside esencial y originariamente en el pueblo y que todo poder público dimana del pueblo y se instituye para beneficio de éste. Sin embargo al tenor del presente ensayo y reconociendo la soberanía específica de la sociedad civil en democracia participativa, el citado artículo 39 bien podría establecer:

Artículo 39: La soberanía nacional reside esencial y originariamente en el pueblo. Todo poder público dimana del pueblo mediante la Democracia Representativa y se instituye para beneficio de éste, mediante la Democracia Participativa de la sociedad civil, en políticas públicas estructurales señaladas en la ley.

Para el caso, él término sociedad civil, como concepto de la ciencia política, designa a la diversidad de personas con categoría de ciudadanos que actúan generalmente de manera organizada para tomar decisiones en el ámbito público que conciernen a todo ciudadano, fuera de las estructuras gubernamentales y al margen de los partidos políticos que operan en la democracia representativa como sociedad política.

Tradicionalmente, siguiendo el concepto de Tocqueville ${ }^{6}$, se identifica sociedad civil con el conjunto de organizaciones e instituciones cívicas voluntarias y sociales que fungen como mediadores entre los individuos y el Estado. Esta definición incluye, pues, tanto a las organizaciones no lucrativas u organizaciones no gubernamentales como a las asociaciones y fundaciones.

La existencia de una sociedad civil diferenciada de la sociedad política, es un prerrequisito para la democracia participativa o democracia en sentido sustantivo. Sin ella, no hay Estado legítimo. Para Habermas ${ }^{7}$, la sociedad civil tiene dos componentes principales: por un lado, el conjunto de instituciones sociales que definen y defienden los derechos que en el caso serían los derechos colectivos de los ciudadanos y que propician su libre asociación en organizaciones de sociedad civil, con la posibilidad de defenderse de la acción estratégica del poder público del Estado y del poder privado del mercado; por otra parte estaría el conjunto de movimientos sociales coyunturalmente organizados que continuamente plantean nuevos principios, valores y demandas sociales. Así, la sociedad civil se define básicamente como una de las tres estructuras del sistema político: sociedad civil demandante que legitima sustantivamente al Estado; régimen político de partidos que legitiman adjetivamente al Estado; y el Estado legitimado que traduce esa legitimidad en políticas públicas, dando lugar al estado de bienestar, en mayor o menor grado.

\footnotetext{
${ }^{6}$ Buqueras y BACH, Ignacio (2002), Más sociedad, menos y mejor estado: pasado, presente y futuro de la sociedad civil, España, Editorial Complutense, [en línea], disponible en: https://books.google.com.mx/books?id=D6V1N7D $J A F o C \&$ printsec $=$ frontcover $d q=M \% C_{3} \% A 1 s+$ sociedad, + menos $+y+$ mejor + estado: + pasa,+ presente $+y+f u t u r o+d e$

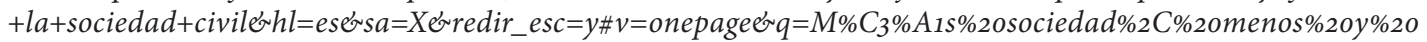
mejor\%2oestado\%3A\%2opasado\%2C\%2opresente\%2oy\%2ofuturo\%2ode\%2ola\%2osociedad\%2ocivilefffalse.

7 Touraine, Alain (1995), ¿Qué es la democracia?, Fondo de Cultura Económica, México, p. 65.
} 


\section{Estado neoconstitucional y democracia participativa soberana}

Hablar de Democracia aún en el presente siglo pudiera resultar, hasta cierto punto, cotidiano y, a la vez, paradigmático. Cotidiano desde la perspectiva de que existen numerosos y valiosos estudios sobre su origen, alcances, visiones y su tropicalización. Paradigmático porque a pesar de todas las contribuciones académicas, en nuestros días la democracia adquiere nuevas connotaciones que la tornan un producto, en términos conceptuales, inacabado ${ }^{8}$.

Aunque no es posible obviar, como lo señaló Bobbio, que la única manera de entenderse cuando se habla de democracia, es considerarla caracterizada por un conjunto de reglas que establecen quién está autorizado para tomar las decisiones colectivas y bajo qué procedimientos?

Si retomamos la idea de una sociedad evolucionada y un contrato social redimensionado, debemos entonces reconsiderar también lo que hasta hoy se ha considerado democracia, pues si bien es cierto que México se configura en una república representativa, democrática, laica, entre otros atributos que le confiere la Constitución Política de los Estados Unidos Mexicanos, hay que vislumbrar que esa democracia, más que una forma de gobierno y un estilo de vida, conlleva a una movilización ciudadana. Y el hecho de que lo refiera como movilización va encaminado a la idea de una democracia participativa eficaz.

En ese orden de ideas, la democracia electiva-participativa, adjetiva-sustantiva o directa-indirecta se dimensiona, en nuestras realidades bajo la concepción de los derechos fundamentales y, representa en la actualidad para el Estado Mexicano uno de sus más grandes retos ${ }^{10}$, más aun considerando la participación como un derecho y una responsabilidad pues si bien es cierto el derecho de participación es el vínculo entre el derecho de autodeterminación política de cada individuo, también es el derecho de autodeterminación de la socieda $d^{11}$, pues independientemente que el individuo pueda ejercer su soberanía mediante la elección de representantes, la Constitución Mexicana también prevé la participación directa a través de los diferentes mecanismos de participación ciudadana ${ }^{12}$.

\footnotetext{
8 Morán Torres, Enoc Francisco (2013), La democracia ante el nuevo paradigma de los derechos humanos en México en Cervantes Bravo Irina y Wong Meráz Víctor Alejandro (coords.) Temas de control de constitucionalidad y convencionalidad en México, México, Porrúa, p. 131-132.

9 Boвbio, Norberto (1986), El futuro de la Democracia, México, Fondo de Cultura Económica, p.14.

${ }^{10}$ Ídem.

Cfr. Artículo 3 de la Constitución Política de los Estados Unidos Mexicanos.

${ }^{11}$ Pérez Royo, Javier (2011), citado por Monroy Cabra, Marco Gerardo, La democracia representativa y participativa en Araujo Oñate, Rocío y Torres Villarreal, María Lucía (Ed.), Retos de la democracia y de la participación ciudadana, Bogotá, Fundación Hanns Seidel, UR, p. 17 [en línea], disponieble en: http://www2.hss. de/fileadmin/americalatina/Colombia/downloads/Retos_de_la_democracia.pdf.

${ }^{12}$ El artículo 35 de la Carta Magna establece que son derechos de los ciudadanos, entre otros, el de iniciar leyes y votar en las consultas populares.

De hecho, el 14 de marzo de 2014 se publicó en el Diario Oficial de la Federación, la Ley Federal de Consulta Popular, reglamentaria de la fracción VIII del artículo 35 de la Constitución General de la República, que tiene por objeto la regulación del procedimiento para la convocatoria, organización, desarrollo, cómputo y declaración de
} 
En efecto, como se ha venido señalando, en los últimos tiempos se hace necesario el fortalecimiento de la Democracia Representativa a través de no sólo el respeto al sufragio sino de una mayor participación de la ciudadanía en asuntos públicos. Ello, debido a que ${ }^{13}$ :

Ya no basta votar y ser votado, el siguiente paso es el incidir de la ciudadanía en los asuntos públicos. Idoneidad de quienes van a representar a los ciudadanos, el sufragio pasivo debe estar sujeto a una amplitud mayor de regulaciones. El ciudadano ya no se conforma con votar cada cierto tiempo, quiere ver consecuencias reales de sus decisiones y tener a la mano formas de incidir de una manera más directa, lo que haría más creíble al sistema ya que el ciudadano se sentiría parte del mismo.

Además de que, en términos de Held, el principio de autonomía democrática conlleva el derecho de todos los ciudadanos a participar y deliberar en las cuestiones públicas ${ }^{14}$.

De hecho, como lo ha establecido el Comité de Derechos Humanos de la Organización de las Naciones Unidas, los ciudadanos también participan en la dirección de los asuntos públicos ejerciendo influencia mediante el debate y el diálogo públicos con sus representantes y gracias a su capacidad para organizarse. Esta participación se respalda garantizando la libertad de expresión, reunión y asociación ${ }^{15}$.

En ese sentido, el concepto de democracia directa implica concepciones minimalistas y maximalistas, las primeras consideran como democracia directa exclusivamente al referendo y las segundas también comprenden la participación ciudadana en las decisiones sobre el uso de los recursos fiscales y en el control de la política permitiendo la concurrencia de los miembros de la comunidad en la toma de las decisiones políticas ${ }^{16}$, siendo en ésta visión maximalista en donde cabe considerar a la sociedad civil como soberana de la democracia directa o democracia participativa.

Si bien es cierto, en el ámbito internacional, el Sistema Interamericano de Derechos Humanos establece en sus diversos ordenamientos que la democracia representativa ${ }^{17}$ constituye una condición indispensable para la estabilidad de la paz y el desarrollo, la Carta Democrática Interamericana contiene disposiciones que fomentan la participación de los ciudadanos en la vida

resultados de la consulta popular, entre otros. Véase SECRETARía DE GobERnACión, Decreto por el que se expide la Ley Federal de Consulta Popular 2014, Diario Oficial de la Federación, 14 de marzo [en línea], disponible en: http://www.dof.gob.mx/nota_detalle.php?codigo=5337123\&fecha=14/03/2014.

13 Dalla Vía Alberto (2011), Derechos Políticos, Normativa Electoral y Equidad en los Procesos Electorales conferencia magistral dictada en el marco del XV Curso Interamericano de Partidos Políticos y Democracia. Construyendo las Condiciones de Equidad en los Procesos Electorales realizado en el Centro de Asesoría y Promoción Electoral del Instituto Interamericano de Derechos Humanos con sede en San José de Costa Rica del 5 al 7 del mes de diciembre.

${ }^{14}$ Held, David (2007), Modelos de Democracia, España, Alianza, tercera edición, p. 395.

15 OrganizaCión de NACiones Unidas, Observación: CCPR-GC-25, la participación en los asuntos públicos y el derecho de voto, Párr. 8. [en línea], disponible en: http://www.bjdh.org.mx/universal/doc?ficha=CCPR_GC_25_ PARR8.

${ }^{16}$ Borea, Alberto, citado en Morán, Torres Enoc Francisco, op cit. nota 9, p. 133.

${ }^{17}$ Hasta este punto consideramos democracia representativa como aquella que otorga el ejercicio de la soberanía con la emisión del voto primordialmente, sin que ello signifique involucrarse en la vida política del Estado 
política y en la toma de decisiones, pues su participación influiría directamente en el diseño de Estado que pretenden vivir o al cual se someten ${ }^{18}$.

En esa línea argumentativa, una democracia participativa incluiría la libertad de los ciudadanos, no sólo para opinar y decidir, votando por la opción que consideren más conveniente, sino también para formarse una opinión al respecto en el marco de una discusión o deliberación abierta entre individuos o grupos organizados, llámese partidos políticos o sociedad civil ${ }^{19}$.

Ello significa la voluntad y necesaria participación de la ciudadanía en asuntos de la agenda política, es decir, involucrase de manera activa en decisiones que correspondan a los representantes, manifestando su opinión e incluso su inconformidad en la toma de decisiones y fortalecer al Estado. Puesto que, en términos de Cunill, es en el Estado donde los derechos se instituyen y se hacen exigibles ${ }^{20}$.

Cabe distinguir que la democracia participativa es un tipo de democracia semidirecta, que surge con la aparición de nuevos mecanismos de participación en los cuales el pueblo adquiere protagonismo como el plebiscito, la consulta, el referéndum, el cabildo abierto, la iniciativa legal y otros modos de participación ${ }^{21}$ a lo que, trasladado a políticas públicas, un pueblo o sociedad que participa activamente en la toma de decisiones tendría que, parafraseando a Sartori, hacer suya la decisión, movilizarse de manera individual y voluntaria para exigir sus derechos y los de sus co-ciudadanos.

Bajo ese enfoque, tomamos la idea de Pascua quien refiere que el elemento esencial de la democracia es la autonomía y el autogobierno, lo que exige una responsabilidad de los ciudadanos a participar en la adopción de decisiones que regirán su vida pues, como señala el autor en comento ${ }^{22}$ :

El activismo de los ciudadanos, es el compromiso cívico que busca soluciones a los problemas comunitarios, es algo imprescindible para el buen funcionamiento de la democracia y para atajar las arbitrariedades de los politicos corruptos. Los pueblos que deploran la corrupción de su clase política están acusándose tácitamente de falta de civismo, pues ese mal no se puede producir

\footnotetext{
${ }^{18}$ Los artículos 6, 11, 13 y 15 de la Carta Democrática Interamericana califican la participación ciudadana como un derecho y una responsabilidad, así como una condición necesaria para el pleno y efectivo ejercicio de la democracia, pues ejercerla implica el desarrollo económico, social y cultural del Estado, además de facilitar el la preservación y adecuado manejo de los derechos de tercera generación, especialmente al medio ambiente, al proponer la implementación de políticas y estrategias para su protección.

Además, la Convención Americana sobre Derechos Humanos, en los artículos 16, parágrafos 1. y 2. 23, parágrafo 1. Inciso a), precisa que todos los ciudadanos deben gozar del derecho de participar en la dirección de los asuntos políticos, directamente o por medio de representantes libremente elegidos y que todas las personas tienen derecho a asociarse con fines ideológicos, religiosos o políticos, entre otros, además que tal derecho sólo puede ser sujeto a las restricciones que sean necesarias en una sociedad democráticas, y que estén previstas en la ley. Véase, Organización de los Estados Americanos (1969), Convención Americana sobre Derechos Humanos, 7 al 22 de noviembre [en línea], disponible en: https://www.oas.org/dil/esp/tratados_B-32_Convencion_Americana_sobre_Derechos_Humanos.htm.

${ }^{19}$ Cfr. Monroy Cabra, Marco Gerardo, op cit. nota 11.

${ }^{20}$ CUnill Grau, Nuria, La construcción de ciudadanía desde una institucionalidad pública ampliada, en Programa de Naciones Unidad Para el Desarrollo Democracia/Estado/Ciudadanía. Hacia un Estado de y para la Democracia en América Latina, Serie Contribuciones al Debate, volumen II, p. 113 [en línea], disponible en: http:// www.iidh.ed.cr/multic/UserFiles/Biblioteca/IIDHSeguridad/12_2010/be846c2a-aoe6-44do-9fae-5d9d637dfgff.pdf

${ }^{21}$ Cfr. Monroy Cabra, Marco Gerardo, op cit. nota 11, p.11.

${ }^{22}$ Íbid.
} 
si los ciudadanos se desentienden de reclamar y desempeñar el papel que les corresponde en la vida pública.

Pese a las distinciones que se hace de la Democracia como derecho ciudadano implica siempre la conjunción de dos principios fundamentales: el principio de la representación y el principio de la participación, que no son excluyentes. Ello es así incluso cuando tengan circunstancialmente peso diverso, como por ejemplo cuando la Democracia, siendo representativa, solo asegure en forma deficiente la participación.

No obstante, no podemos hablar de una Democracia que sea participativa, sin que exista representación. Es decir, una Democracia Representativa que no asegura la efectiva participación se considera deficiente; pero una Democracia Participativa que no asegura la representación ni siquiera pudiera existir, ante tal afirmación, bajo ningún supuesto podríamos renegar de la Democracia Representativa para abrir paso a una Democracia exclusivamente participativa.

Sin embargo en el texto constitucional ya citado, se podría agregar la democracia participativa con carácter de soberanía racional, instrumentalizada mediante la técnica de las políticas públicas focalizadas y votadas por ciudadanos en grupos sociales organizados de la sociedad civil; diferenciándola de la democracia representativa que por su propia naturaleza de competencia entre partidos políticos, lleva al pueblo a un ejercicio de soberanía menos racional.

\section{Conclusiones}

Cuando planteamos la interrogante de diseñar o rediseñar un modelo constitucional que permita una sociedad civil soberana titular del ejercicio de la Democracia Participativa, se hace en el sentido de que dicha sociedad civil, al poseer el interés legítimo, se encuentra facultada para representar a la colectividad o a la comunidad organizada en la salvaguarda de los derechos de tercera generación, que al ser colectivos, son proclives a su instrumentalización mediante la técnica de las políticas públicas.

Lo anterior lleva a la necesidad de plantear una reforma constitucional, en que si bien, la soberanía nacional reside esencial y originariamente en el pueblo y todo poder público dimana de éste, mediante la Democracia Representativa en el ejercicio electoral impulsado por los partidos políticos; sin embargo para que dicho poder quede instituido para beneficio eficaz del pueblo, se hace necesaria la democracia participativa de la sociedad civil, en políticas públicas estructurales, empleando mecanismos de participación ciudadana como es la consulta popular y como una exigencia constitucional, para someter a evaluación las políticas públicas de los derechos colectivos.

En la tesitura anterior, llegaríamos a un Estado verdaderamente neoconstitucional en los derechos de tercera generación, a partir de que Prieto Sanchís, adoptando el esquema propuesto por Comanducci, señala que hay al menos cuatro acepciones principales del neoconstitucionalismo: En primer lugar, el constitucionalismo puede encarnar un tipo de estado de derecho. En segundo lugar, el constitucionalismo es una teoría del derecho. En tercer lugar, el constitucionalismo cabe entender la ideología o filosofía política Y finalmente en cuarto lugar, el constitucionalismo, en un sentido lato, puede llamarse filosofía jurídica ${ }^{23}$.

Es así que se propone bajo esta última perspectiva de Neoconstitucionalismo, un nuevo modelo de diseño constitucional en el que la sociedad civil, como una de las tres estructuras del

${ }^{23}$ Prieto Sanchís, Luis (2003), Justicia constitucional y derechos fundamentales, Trotta, Madrid, p. 101-102. 
sistema político, se erige en titular de la soberanía en el ejercicio de la Democracia Participativa, en derechos de tercera generación que al tener carácter colectivo, requieren de mayor legitimación para su operación en política pública, por parte del Estado-Gobierno.

\section{Fuentes de consulta}

Boвbio, Norberto (1986), El futuro de la Democracia, México, Fondo de Cultura Económica.

Buqueras y BACH, Ignacio (2002), Más sociedad, menos y mejor estado: pasado, presente y futuro de la sociedad civil, Editorial Complutense, [en línea], disponible en: https://books. google.com.mx/books?id=D6V1N7DJAFoC\&printsec=frontcover\&dq=M\%C $3 \% A 1 s+$ socie dad,+menos $+y+$ mejor + estado: + pasado, + presente $+y+f u t u r o+d e+l a+$ sociedad + civil\& $h l=$

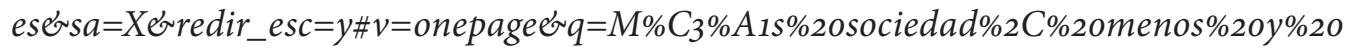
mejor\%2oestado\%3A\%2opasado\%2C\%2opresente\%2oy\%2ofuturo\%2ode\%2ola\%2osociedad\%2ocivilef $f$ false.

Cunill Grau, Nuria, La construcción de ciudadanía desde una institucionalidad pública ampliada, en Programa de Naciones Unidad Para el Desarrollo Democracia/Estado/Ciudadanía. Hacia un Estado de y para la Democracia en América Latina, Serie Contribuciones al Debate, volumen II, [en línea], disponible en: http://www.iidh.ed.cr/multic/ UserFiles/Biblioteca/IIDHSeguridad/12_2010/be846c2a-aoe6-44do-9fae-5d9d637dfgff.pdf.

Dalla Vía, Alberto (2001), Derechos Políticos, Normativa Electoral y Equidad en los Procesos Electorales conferencia magistral dictada en el marco del XV Curso Interamericano de Partidos Políticos y Democracia. Construyendo las Condiciones de Equidad en los Procesos Electorales realizado en el Centro de Asesoría y Promoción Electoral del Instituto Interamericano de Derechos Humanos con sede en San José de Costa Rica del 5 al 7 del mes de diciembre.

Held, David (2007), Modelos de Democracia, España, Alianza, tercera edición.

Monroy Cabra, Marco Gerardo (2011), La democracia representativa y participativa en Araujo Oñate, Rocío y Torres Villarreal, María Lucía (Ed.) Retos de la democracia y de la participación ciudadana, Bogotá, Fundación Hanns Seidel, UR, 4p. [en líena], disponible en: http://www.hss.de/fileadmin/americalatina/Colombia/downloads/Retos_de_la_democracia.pdf

Morán Torres, Enoc Francisco (2013), La democracia ante el nuevo paradigma de los derechos humanos en México en Cervantes Bravo Irina y Wong Meraz Víctor Alejandro (Coords.) Temas de control de constitucionalidad y convencionalidad en México, México, Porrúa.

Organización de Estados Americanos. Carta Democrática Interamericana [en línea], disponible en: http://www.oas.org/charter/docs_es/resolucion1_es.htm

Convención Americana sobre Derechos Humanos, 7 al 22 de noviembre de 1969 [en línea], disponible en: https://www.oas.org/dil/esp/tratados_B-32_Convencion_Americana_sobre_Derechos_Humanos.htm. 
Organización de las Naciones Unidas (1984), Declaración sobre el derecho de los pueblos a la paz, 12 de noviembre, [en línea], disponible en: http://www.ohchr.org/SP/Professionalinterest/Pages/RightOfPeoplesToPeace.aspx.

, Observación: CCPR-GC-25, la participación en los asuntos públicos y el derecho de voto, Párr. 8. [en línea], disponible en: http://www.bjdh.org.mx/universal/ doc?ficha=CCPR_GC_25_PARR8.

, Pacto Internacional de Derechos Civiles y Políticos, 16 de diciembre de 1966, [en línea], disponible en: $h t t p: / / w w w . o h c h r . o r g / S P / P r o f e s s i o n a l I n t e r e s t / P a g e s / C C P R . a s p x$.

, Pacto Internacional de Derechos Económicos, Sociales y Culturales, 16 de diciembre de 1966 [en línea], disponible en: http://www.ohchr.org/SP/ProfessionalInterest/Pages/ CCPR.aspx.

Paoli Bolio, Francisco José (2009), Teoría del Estado, Trillas, México.

Pérez Luño, Antonio (2006), La Tercera Generación de los Derechos Humanos, Aranzadi, España.

PÉrez Royo, Javier (2011), citado por Monroy Cabra, Marco Gerardo. La democracia representativa y participativa en Araujo Oñate, Rocío y Torres Villarreal, María Lucía (Ed.) Retos de la democracia y de la participación ciudadana, Fundación Hanns Seidel, UR, Bogotá [en línea], disponible en: http://www2.hss.de/fileadmin/americalatina/Colombia/downloads/Retos_de_la_democracia.pdf

Prieto Sanchís, Luis (2003), Justicia constitucional y derechos fundamentales, Trotta, Madrid.

Secretaría de Gobernación (2014), Decreto por el que se expide la Ley Federal de Consulta Popular, Diario Oficial de la Federación, 14 de marzo [en línea], disponible en: http:// $w w w . d o f . g o b . m x /$ nota_detalle.php?codigo $=5337123 \&$ fecha $=14 / 03 / 2014$.

Tour aine, Alain (1995), ¿Qué es la democracia?, Fondo de Cultura Económica, México. 